\title{
Bacteriological Profile and Antimicrobial Resistance Pattern in Surgical Site Infection in a Tertiary Care Hospital, Central Nepal
}

\author{
Beena Jha', Saroj Gautam ${ }^{2}$, Jyotshna Sharma ${ }^{3}$ and Manisha Sharma ${ }^{1}$ \\ ${ }^{1}$ Department of Microbiology, Kathmandu Medical College and Teaching Hospital, Duwakot, Kathmandu, \\ Nepal \\ ${ }^{2}$ Department of Orthopedic Surgery, Kathmandu Medical College, Sinamangal, Kathmandu, Nepal \\ ${ }^{3}$ Department of Obstetrics and Gynaecology, Kathmandu Medical College, Sinamangal, Kathmandu, Nepal
}

\begin{abstract}
Introduction: Surgical site wound infections (SSI) are the third most commonly reported nosocomial infection and they account for approximately a quarter of all nosocomial infections. Apart from bacterial contamination of wound, various patient and environment related factors play a role in development and outcome of SSI. The present study is undertaken to study the frequency of SSI and the antimicrobial resistance pattern of the causative organisms isolated.

Methods: This cross-sectional prospective study was carried out over a period of one year. A total of 245 pus samples from suspected cases of surgical site infections were processed for gram staining, culture, biochemical identification tests and antimicrobial susceptibility testing using standard microbiological protocol. Data was analysed using software word version SPSS 19.

Results: The overall frequency of SSI was $13.87 \%$. Most common isolates were staphylococcus aureus and Escherichia coli. All four staph aureus strains were resistant to penicillin and cefixime but were $100 \%$ sensitive to vancomycin and cloxacillin. Two out of four stains were methicillin resistant Staph. aureus (MRSA). Another concern in recent time is the isolation of acinetobacter from surgical wounds.

Conclusions: Preoperative antibiotics, reduced hospital stay and proper control of co-morbidities decrease the incidence of post-operative infections. Marked resistance of isolates to commonly used antibiotics signifies the need for judicious and rational use of these drugs to prevent the emergence of antibiotic resistant strains.

Keywords: Clean and clean-contaminated wound; MRSA; Post-operative wound infections; Staphylococcus aureus; Surgical site infections
\end{abstract}

Correspondence: Beena Jha, Department of Microbiology, Kathmandu Medical College and Teaching Hospital, Duwakot, Kathmandu, Nepal. Email: drbeenajha@gmail.com

DOI: $10.3126 / \mathrm{mj}$ sbh.v20i2.33399

Submitted on: 2020-12-14

Accepted on: 2021-06-10 


\section{INTRODUCTION}

Surgical site infection (SSI) usually appears after three to seven days post-procedure. It may however develop up to 30 days and even up to one year, especially in patients with implants. SSI are the third most commonly reported nosocomial infections and they account for approximately a quarter of all nosocomial infections. ${ }^{1}$ It is a major cause of increased morbidity as well as mortality among post-operative patients and increased cost of healthcare in most centres all around the globe. ${ }^{2}$ The incidence of SSI in developing countries has been reported to be around two to $40 \%$. In many SSIs, the responsible pathogens originate from patient's endogenous flora. The causative pathogen depends on the type of surgery; the most commonly isolated organisms are staphylococcus aureus, coagulase negative staphylococci, enterococcus spp and Escherichia coli. ${ }^{3}$ For any given type of surgery, SSI approximately doubles the cost of hospitalisation..$^{6-8}$ This study is aimed to provide the knowledge of the organisms causing SSI and help in rational use of antibiotics based on their resistant pattern towards different antibiotics. We intended to find the incidence of SSI and bacteriological profile of organisms causing SSI with their antibiotic resistance pattern in post-operative patients.

\section{METHODS}

The study was commenced after taking permission from Institutional Review Committee of our institute. It was a cross-sectional prospective study conducted from $1^{\text {st }}$ Aug 2019 to $31^{\text {st }}$ Jul 2020, at Kathmandu Medical College and Teaching Hospital, Sinamangal, Kathmandu, Nepal. Sample size was calculated from the study conducted in tertiary care hospital in India which was approximately $20 \%{ }^{4}$

$\mathrm{P}^{4}(\mathrm{P}=20 \%)$

$\mathrm{Z}=1.96$

$\mathrm{Q}=80$

Sample size $=\mathrm{Z}^{2} \mathrm{PQ} / \mathrm{d}^{2}$

$\mathrm{n}=3.84 \times 20 \times 80 / 25=245.76$

Sample size $=245$

Patients of either sex, admitted in the Department of Surgery, Department of Orthopaedics, Department of Gynaecology and Obstetrics, who had undergone surgical procedures during the study period were enrolled into the study after taking informed consent. Convenient sampling method was used. Surgical wound was examined on third operative day and thereafter weekly for 30 days. A total of 245 pus samples from suspected cases of surgical site were collected using two sterile swab without contaminating with skin commensals under aseptic conditions. Smear was prepared directly from sample using the first swab and stained with gram stain. Culture was done from second swab, labeled and transported to the clinical microbiology laboratory without any delay. All samples were inoculated on to blood, MacConkey and Chocolate agar plates aerobically and incubated at $37^{\circ} \mathrm{C}$ for 48 hours. Organism isolates were identified by gram staining, their colony characteristics and biochemical test.

All the bacterial isolates were subjected to antimicrobial susceptibility test by modified KirbyBauer disc diffusion method on Mueller-Hinton agar (HI- Media). After matching with 0.5 McFarland Unit, entire MHA plate was inoculated with sterile cotton swab by lawn culture method. Antibiotics from Hi-Media were laid over it with the help of forceps. Antibiotics used were Imipenem $(10 \mu \mathrm{g})$, Amikacin $(30 \mu \mathrm{g})$, Amoxyclav $(20 / 10 \mu \mathrm{g})$, Cloxacillin $(30 \mu \mathrm{g})$, Cefixime $(5 \mu \mathrm{g})$, Ceftriaxone $(5 \mu \mathrm{g})$, Azithromycin $(15 \mu \mathrm{g})$, Cotrimoxazole $(23.75 / 1.25 \mu \mathrm{g})$, Piperacillin / Tazobactam $(100 / 10 \mu \mathrm{g})$, Ofloxacillin $(5 \mu \mathrm{g})$, Ampicillin $(10 \mu \mathrm{g})$, Vancomycin $(30 \mu \mathrm{g})$, Colistin $(10 \mu \mathrm{g})$ and Tigecycline $(15 \mu \mathrm{g})$. Plates were incubated aerobically for 24 hours at $37^{\circ} \mathrm{C} .{ }^{5}$ The zone of inhibition were compared with the standard interpretative table as per CLSI guidelines 2012. Data was analysed by using SPSS software word version 19.

\section{RESULT}

Among total 245 patients, SSI was $15(44 \%)$ in surgery department, 11 (32\%) in orthopaedic department and rest 8 (23\%) was from gynaecology and obstetrics department. Thirty four (13.87\%) patients developed SSI out of which only 10 were found to be culture positive. SSI rate was $5.5 \%$ in clean surgeries and $36.92 \%$ in clean-contaminated surgeries as shown in Table 1.

SSI rate was found to be higher among females $[19(55.80 \%)]$ than male patients [15(44.11\%)]. 
Table 1. Incidence of SSI with respect to wound class

\begin{tabular}{|l|r|r|}
\hline Wound class & $\begin{array}{c}\text { No. of patients } \\
(\%)\end{array}$ & \multicolumn{1}{|c|}{$\begin{array}{c}\text { Wound class } \\
(\%)\end{array}$} \\
\hline Clean & $180(73.46)$ & $10(5.55)$ \\
$\begin{array}{l}\text { Clean and } \\
\text { contaminated }\end{array}$ & $65(26.53)$ & $24(36.92)$ \\
\hline Total & $245(100)$ & $34(13.87)$ \\
\hline
\end{tabular}

However, this difference was not statistically significant. Highest incidence of SSI was found among age group of 40 to 60 years [15(44.11\%)] and least below the age of 20 years.

S. aureus was the most common organism isolated, accounting for $40 \%$ (4 isolates) followed by Escherichia coli (2 isolates, 30\%), Citrobacter freundii (2 isolates, 20\%) and coagulase negative $S$. aureus (1 isolate, 10\%) and Acinetobacter boumanii (1 isolate, $10 \%$ ) as shown in table 3 .

All the four s. aureus strains were $100 \%$ resistant to ampicillin and cefixime but were $100 \%$ sensitive to vancomycin and cloxacillin ( $0 \%$ resistant). Two out of four stains were methicillin resistant $S$. aureus (MRSA).

Antibiogram of E. coli exhibited $100 \%$ resistant to imipenem and piperacillin - tazobactam and showed $100 \%$ sensitive to newer drugs tigecycline and colistin. Moderate susceptibility was seen to ofloxacin, ceftriaxone, and amikacin. Acinetobacter baumanii were resistant to most of the drugs used and was having good susceptibility towards only colistin and tigecycline. On the other hand, citrobacter freundii showed resistant to the newer drugs colistin and tigecycline and was sensitive to other commonly used drugs.

Table 3. Frequency of pathogenic bacterial isolates

\begin{tabular}{|l|r|r|}
\hline Organism detected & $\begin{array}{c}\text { Number of } \\
\text { isolates }\end{array}$ & $\begin{array}{l}\% \text { of total } \\
\text { isolates }\end{array}$ \\
\hline S aureus & 4 & 40 \\
E. coli & 2 & 20 \\
C. freundii & 2 & 20 \\
Acinetobacter baumanii & 1 & 10 \\
CONS & 1 & 10
\end{tabular}

Table 2. Demographic characteristics of study

\begin{tabular}{|l|l|r|}
\hline Character & & $\mathrm{N}(\%)$ \\
\hline Gender & Female & $137(55)$ \\
& Male & $108(44)$ \\
\hline Age category & $<20$ & $14(5)$ \\
& $21-40$ & $86(35)$ \\
& $41-60$ & $108(44)$ \\
& $>60$ & $28(11)$ \\
\hline
\end{tabular}

\section{DISCUSSION}

The SSI incidence rate of the present study is $13.87 \%$ which can be well correlated with the infection rates of $4.7 \%, 9.6 \%, 12.6 \%$ to $23 \%$ in Nepal conducted by Tuladhar et al., Sutariya et al., Shrestha et al. and Giri et al. respectively between 2008-2017.9-12 Various studies conducted in developing countries including India showed SSI rate between $6 \%$ to $32 \% .{ }^{13-19}$ However, reports from other developed countries showed a lower incidence of SSI between $2.8 \%$ and $16 \%{ }^{20-23}$ SSI rates assessed in a Canadian hospital over a prolonged period of 10 to 16 years showed a rate of only $4.7 \%$ which indicates that larger groups studied over a longer duration give a better assessment of SSI rates. The difference observed in the incidence rate of SSI in developed countries compared to developing countries, could be due to poor set-up of hospitals, poor hygiene of patients increasing colonisation of skin by bacterial flora,

Table 4. Antibiotic resistance pattern of Gram-positive bacterial isolates

\begin{tabular}{|c|c|c|c|c|c|c|}
\hline \multirow[t]{2}{*}{ Antimicrobials } & \multicolumn{2}{|c|}{ MSSA } & \multicolumn{2}{|c|}{ MRSA } & \multicolumn{2}{|c|}{ CONS } \\
\hline & $\mathbf{N}$ & $\%$ & $\mathbf{N}$ & $\%$ & $\mathbf{N}$ & $\%$ \\
\hline Ampicillin & 02 & 100 & 02 & 100 & 01 & 100 \\
\hline Azithromycin & 01 & 50 & 02 & 100 & 01 & 100 \\
\hline Cefixime & 02 & 100 & 02 & 100 & 01 & 100 \\
\hline Ofloxacin & 00 & 00.0 & 02 & 100 & 01 & 100 \\
\hline Amikacin & 00 & 00.0 & 02 & 100 & 00 & 00.0 \\
\hline Cotrimoxazole & 01 & 50 & 02 & 100 & 01 & 100 \\
\hline Ceftriaxone & 00 & 00.0 & 02 & 100 & 01 & 100 \\
\hline Cloxacillin & 01 & 50 & 00 & 00.0 & 01 & 100 \\
\hline Vancomycin & 00 & 00.0 & 00 & 00.0 & 00 & 00.0 \\
\hline
\end{tabular}


Table 5. Antibiotic resistance pattern of Gramnegative bacterial isolates

\begin{tabular}{|c|c|c|c|c|c|c|}
\hline \multirow[t]{2}{*}{ Antimicrobials } & \multicolumn{2}{|c|}{ E.coli } & \multicolumn{2}{|c|}{$\begin{array}{l}\text { Citro- } \\
\text { bacter } \\
\text { freundii }\end{array}$} & \multicolumn{2}{|c|}{$\begin{array}{l}\text { Acineto- } \\
\text { bacter } \\
\text { baumanii }\end{array}$} \\
\hline & $\mathbf{N}$ & $\%$ & $\mathbf{N}$ & $\%$ & $\mathbf{N}$ & $\%$ \\
\hline Imipenem & 02 & 100 & 00 & 00.0 & 01 & 100 \\
\hline Azithromycin & 01 & 50 & 00 & 00.0 & 01 & 100 \\
\hline Amoxyclav & 01 & 50 & 01 & 50 & 01 & 100 \\
\hline Cefixime & 01 & 50 & 00 & 00.0 & 01 & 100 \\
\hline Ofloxacin & 01 & 50 & 00 & 00.0 & 01 & 100 \\
\hline Amikacin & 01 & 50 & 00 & 00.0 & 01 & 100 \\
\hline Cotrimoxazole & 01 & 50 & 00 & 00.0 & 01 & 100 \\
\hline Ceftriaxone & 01 & 50 & 00 & 00.0 & 01 & 100 \\
\hline Tigecycline & 00 & 00.0 & 00 & 00.0 & 00 & 00.0 \\
\hline Colistin & 00 & 00.0 & 02 & 100 & 00 & 00.0 \\
\hline $\begin{array}{l}\text { Piperacillin- } \\
\text { Tazobactam }\end{array}$ & 02 & 100 & 00 & 00.0 & 01 & 100 \\
\hline
\end{tabular}

late presentation of patients to healthcare system leading to contaminated wounds, and overwhelmed emergency services due to population burden. A higher infection rate in developing countries emphasises the need for better implementation of infection control practices along with a proper surveillance system for the use of antibiotics.

The higher frequency of SSI observed in Department of Surgery [15 (44\%)] could be because of higher number of emergency procedures conducted in this department in comparison to other departments. Highest incidence of SSI was found among age group of 40 to 60 years [15 (44.11\%)]. This result was in agreement with other studies confirming that as age increases the risk occurrence of SSIs also increases. ${ }^{24}$

In the present study, $S$. aureus was the commonest isolate from the postoperative wound infection which is in consistent with reports from other studies. ${ }^{1,20,25}$ Among gram negative bacilli, E. coli was the commonest isolate in the present study. Based on the type of surgical procedure, the pathogens that are isolated from SSI may vary. It is found that in clean surgical procedures, s. aureus is the usual pathogen isolated from the exogenous environment or the patient's skin flora and anterior nares. In the present study gram negative bacilli were predominantly isolated from clean- contaminated surgeries. These are the polymicrobial flora closely resembling the normal endogenous microflora of the surgically resected organ most frequently isolated. ${ }^{26}$

A number of studies in the literature indicate gradual increase in the emergence of antibiotic resistant microorganisms in surgical patients. ${ }^{26-27}$ Special interest in s. aureus SSI is mainly due to its predominant role in hospital cross infection and emergence of virulent antibiotic resistant strains. In the present study, all $S$. aureus strains from the infected wound were resistant to cefixime and ampicillin. Ampicillin resistance in s. aureus has been reported in other studies also. ${ }^{28}$ Two out of four $(50 \%)$ strains of $S$. aureus strains were methicillin-resistant but none of the strains was resistant to vancomycin and cloxacillin. In the 2010 National Healthcare Safety Network (NHSN) update, the portion of SSI due to MRSA was $43.7 \%{ }^{29}$

E. coli was the commonest gram negative organism isolated from our study which is in accordance to a study conducted in India by Singh et al. ${ }^{30}$ All strains of $E$. coli in our study were resistant to imipenem and piperacillin - tazobactam. Fifty percent of $E$. coli isolates were resistant to the combination of amoxicillin and clavulanate. This finding suggests that the resistance observed was mainly due to the production of $\beta$-lactamase by the organisms. In addition, most isolates were susceptible to colistin and tigecycline but $50 \%$ were resistant to ceftriaxone which is one of the drugs commonly used for prophylaxis.

SSI due to $A$. baumanii, though uncommon, does occur and is increasing in frequency. In our study, A. baumanii isolated were multi drug resistant and were effective only with reserved drugs colistin and tigecycline. Tigecycline has good in vitro activity against imipenem-resistant acinetobacter, showing $100 \%$ sensitivity.

Prolonged postoperative hospitalisation, which is a major concern of most of the hospitals, has been evident in patients developing SSI. ${ }^{30}$ Though the exact increase in patient-care cost due to prolonged postoperative hospital stay could not be calculated, it is a cause of concern for any hospital. Surveillance of SSI with feedback of appropriate 
data to surgeons would be desirable to reduce the SSI rate. Although our study is a single centric small sized study, we believe it has been able to shed the light upon the present scenario of SSI and the common antibiotics resistance and sensitivity pattern. Another important limitation of our study is that we did not culture anaerobic bacteria. SSI with negative cultures may be positive for anaerobic bacteria.

\section{CONCLUSIONS}

We found out that SSI incidence rate to be $13.8 \%$, which was within acceptable international ranges. However, multi-drug resistance was exhibited by
MRSA, E. coli and acinetobacter isolates, leaving clinicians with few choices of drugs for the treatment of patients with SSI. Emergence of drug resistant strains of acinetobacter exhibit significant role in hospital acquired infection.

To cite this article: Jha B, Gautam S, Sharma J, Sharma M. Bacteriological Profile and Antimicrobial Resistance Pattern in Surgical Site Infection in a Tertiary Care Hospital, Central Nepal. MJSBH. 2021;20(2):110-5.

Conflict of Interest: None declared

\section{REFERENCES}

1. Mangram AJ, Horan TC, Pearson ML, Silver LC, Jarvis WR. The Hospital Infection Control Practices Advisory Committee. Guideline for prevention of surgical site infection. Infect Control Hosp Epidemiol. 1999;20:247-78. DOI:https://pubmed.ncbi.nlm.nih.gov/10196487/

2. Yalcin AN, Bakir M, Bakici Z, Dokmetas I, Sabir N. Postoperative wound infections. J Hosp Infect. 1995;29:305-9. DOI:http://dx.doi.org/10.18203/2394-6040.ijemph20170063

3. Owens CD, Stoessel K. Surgical Site Infections: epidemiology, microbiology and prevention. J Hosp Infect. 2008;70(1-2):3-10. DOI:http://dx.doi.org/10.18203/2320-6012.ijrms20161922.

4. Mahesh CB, Shivakumar S, Suresh BS, Chidanand SP, Vishwanath Y. A prospective study of surgical site infections in a teaching hospital. J Clin Diagn Res. 2010;4:3114-9. DOI:10.1007/s12262-008-0031-y.

5. Collee JG, Miles RS, Watt B. Tests for identification of bacteria. In: Collee JG, Fraser AG, Marmion BP, Simmons A. (Eds.) Mackie and McCartney's Practical Medical Microbiology. 14th Edn. London: Churchill Livingstone. 2006:131-49.

6. Dellinger EP, Ehrenkranz NJ. Surgical Infections. In: Bennett JV, Brachnan PS, editor. Hospital Infections. 4th ed. Philadelphia: Lippincott Raven publishers; 1998. p. 571-86.

7. Razavi SM, Ibrahimpoor M, Kashani AS, Jafarani A. Abdominal surgical site infections: Incidence and risk factors at an Iranian teaching hospital. BMC Surg. 2005;5(1):2-5. DOI: 10.1186/1471-2482-5-2.

8. Nandi PL, Rajan SS, Mak KC, Chan SC, So YP. Surgical wound infection. Hong Kong Med J. 1999;5:82-6. DOI: https://hub.hku.hk/bitstream/10722/45397/1/41023.pdf.

9. Tuladhar NR, Ghimire P, Bhatta DR, Banjara MR, Sharma AP, Joshi AB. Surgical Wound Infections in Patients of Tribhuvan University Teaching Hospital. J Nepal Health Res Council. 2008;1(1):5-11. DOI:https://doi.org/ 10.33314/jnhrc.v1i1.20

10. Sutariya PK, Chavada MV. Incidence and determinants of the surgical site infection: a hospital based longitudinal study. Int Surg J. 2016;3(4):2202-6. DOI:http://dx.doi.org/10.18203/2349-2902.isj20163601.

11. Shrestha S, Shrestha R, Shrestha B, Dongol A. Incidence and Risk Factors of Surgical Site Infection Following Cesarean Section at Dhulikhel Hospital. KUMJ. 2014;12(46):113-6. DOI: https://doi.org/10.3126/ kumj.v12i2.13656.

12. Giri S, Kandel BP, Pant S, Lakhey PL, Singh YP, Vaidya P. Risk factors for surgical site infections in abdominal surgery: a study in Nepal. Surg Infect. 2013;14(3):313-8. DOI: 10.1089/sur.2012.108. 
13. Shahane V, Bhawal S, Lele U. Surgical site infections: A one year prospective study in a tertiary care centre. Int $\mathrm{J}$ Health Sci (Qassim). 2012;6(1):79-84. DOI: 10.12816/0005976.

14. Lilani SP, Jangale N, Chowdhary A, Daver GB. Surgical site infection in clean and clean-contaminated cases. Indian J Med Microbiol. 2005 Oct;23(4):249-52. PMID: 16327121.

15. Narula H, Chikara G, Gupta P. A prospective study on bacteriological profile and antibiogram of postoperative wound infections in a tertiary care hospital in Western Rajasthan. J Family Med Prim Care. 2020;9:1927-34. DOI: https://www.jfmpc.com/text.asp?2020/9/4/1927-34.

16. Abubaker L, Bazira J, Najjuka JL. Incidence and Etiology of Surgical Site Infections among Emergency Postoperative Patients in Mbarara Regional Referral Hospital, South Western Uganda. Surg Res Practice. 2017(1): 1-6. DOI:https://doi.org/10.1155/2017/6365172.

17. Saxena A, Singh MP, Brahmchari S, Banerjee M. Surgical site Infection among postoperative patients of tertiary care centre in Central India. Asian j biomed pharm.. 2013;3(17):41-4.

18. Mundhada AS, Tenpe S. A study of organisms causing surgical site infections and their antimicrobial susceptibility in a tertiary care Government Hospital. Indian J Pathol Microbiol. 2015;58:195-200. DOI:https:// www.ijpmonline.org/text.asp?2015/58/2/195/155313.

19. Olson M, O'Connor M, Schwartz ML. Surgical wound infections. A 5-year prospective study of 20,193 wounds at the Minneapolis VA Medical Center. Ann Surg. 1984;199:253-9. DOI: 10.1097/00000658-198403000-00001.

20. Wanger MB, da Silva NB, Vinciprova AR, Becker AB, Burtet LM, Hall AJ. Hospital acquired infection among surgical patients in a Brazilian hospital. J Hosp Infect. 1997;35:277-85. DOI:10.1097/00000658-198403000-00001.

21. Soleto L, Pirard M, Boelaret M. Incidence of surgical site infection and the validity of the National Nosocomial Infection Surveillance System risk index in a general surgical ward in Santa Cruz, Bolivia. Infect Control Hosp Epidemiol. 2003;24:26-30. DOI:10.1086/502111.

22. Eriksen HM, Chugulu S, Kondo S, Lingaas E. Surgical site infections at Kilimanjaro, Christian Medical Centre. J Hosp Infect. 2003;55:14-20. DOI: https://doi.org/10.1016/S0195-6701(03)00225-1

23. Lalato TL, Gemeda GH, Abdella SH. Incidence and predictors of surgical site infection in Ethiopia: prospective cohort. BMC Infect Dis. 2017;17:119. DOI: 10.1186/s12879-016-2167-X.

24. Prabhakar H, Arora S. A bacteriological study of wound infections. J Indian Med Assoc. 1979;73:145-8. PMID: 547003.

25. Nichols RL. Surgical wound infection. Am J Med. 1991;91:54S-63S. DOI:10.3201/eid0702.010214.

26. Kowli SS, Nayak MH, Mehta AP, Bhalerao RA. Hospital infection. Indian J Surg. 1985;48:475-86.

27. Anvikar AR, Deshmukh AB, Karyakarte RP, Damle AS, Patwardhan NS, Malik AK, et al. A one year prospective study of 3,280 surgical wounds. Indian J Med Microbiol. 1999;17:129-32.

28. Young PY, Khadaroo RG. Surgical site infections. Surg clin North Am. 2014;94(6):1245-64. DOI: 10.1016/j.suc. 2014.08,008. PMID :25440122.

29. Singh R, Sikka R, Maggu NK. Prevalence and antibiotic sensitivity pattern of bacteria isolated from nosocomial infections in orthopedic patients. J Orthop. 2010;7(2):e3. DOI:10.1089/sur.2014.187.

30. Cruse Peter JE, Foord R. The epidemiology of wound infection. A 10-year prospective study of 62,939 wounds. Surg Clin North Am. 1980;60:27-40. DOI:10.1016/s0039-6109(16)42031-1. 